\title{
Investigating the Correlation between Food Prices and University Students Awareness of the Effects of Fast Food Consumption on their Health Nouf Al-Aklabi ${ }^{1}$, Wejdan Al-Dowsari ${ }^{1}$ and Despena Andrioti ${ }^{*}$ \\ ${ }^{1}$ College of Health and Rehabilitation Sciences, Princess Nora University, Riyadh, Kingdom of Saudi Arabia ${ }^{2}$ Centre of Maritime Health and Society, Institute of Public Health, School of Health Sciences, University of Southern Denmark, Denmark
}

\section{Abstract}

Background: The price of a given food product is an indicative measure of its nutritious value. For this reason, people belonging to low-income groups are specifically vulnerable to malnutrition. This study aims to identify nutritional patterns among students at the Princess Nora University, Riyadh, Saudi Arabia, quantify students' level of awareness of health risks associated with fast food consumption, examine how price affects their choice of food, and provide general guidelines for improving students nutrition.

Methods: Quantitative data, gathered from distributing a standard questionnaire, was complemented with qualitative observational data using an observation checklist. The sample was 100 female students who eat at the University canteen. The study was conducted between October-December 2015. Data analysis was done using Excel to calculate frequencies of the respective variables.

Results: Fast food prices are notably lower than healthier food choices in the University restaurants. Price is indeed a determining factor for food choice among students, which is to be expected given that the majority of them belong to middle or low income social groups. Students seem to be adequately aware of possible health issues originating from fast food consumption, but many choose to ignore them for financial reasons or lack of motivation.

Conclusion: A sustained public health effort should be undertaken involving the leadership of the University and the students to ease the financial burden for the less wealthy, and make nutritious food choices available and identifiable.

\section{Introduction}

Food choice is influenced by a number of variables such as income, globalization, nutritional behavior transitions and market prices. Prices of essential food products change considerably over time [1]. Health economists found that individuals would rather pay the smallest price available for foods or services. Human behaviour is usually influenced by many factors, especially with regards to their budget $[2,3]$.

Price directly determines the quality of the food consumed. For instance, consumers will choose the cheapest product rather than the healthiest one. Several studies have shown that healthy food costs more, so that tends to increase the number of consumers of less nutritious products. The low-income populations are at most risk because, in contrast to high and middle-income groups, they are mostly unable to afford healthy nutrition [4]. Due to the rapid increase of food prices $[4,5]$ an intervention is deemed necessary so that inequalities in quality food access are reduced [6,7].

Consuming food poor in nutritional value (fast food, chips and soft drinks) is associated with chronic diseases such as diabetes, obesity and cardiovascular diseases (CVD) including stroke and hypertension [8]. Consuming healthy food on the other hand could prevent many chronic diseases and enhance overall health $[9,10]$. A meta-analysis based on twenty-seven studies from ten different countries investigated the differences in price of healthy versus unhealthy food, and focused on the challenges and opportunities to reduce the financial burdens for the less wealthy. This meta-analysis also addressed important questions such as why healthier food should cost more even though consuming it enhances the overall health of the individual and reduces incidences of chronic disease [8].

Public health professionals have suggested policies to financially tax unhealthy food consumption. This proved to reduce the number of fast food consumers and encourage people to eat healthily and promote healthy alternatives. Making healthier foods affordable could be an evidence-based intervention to balance price differences $[10,11]$.

Social inequalities regarding food quality arising from price differences are observed in the most industrialized countries, such as the United States (USA) 12 and France13. The price of healthy foods in the United States during the period 1980-2006 increased whereas unhealthy foods during the same period became cheaper [12]. Several studies reveal that the growing obesity rate among the US population is directly related to the decrement in costs of low nutritional value foods and the simultaneous increase in price of nutritious food [14].

In France for example, vegetable prices have increased dramatically, whereas prices for sweets and fatty foods dropped [13]. The previous studies illustrate the current situation of food price differences globally, but any implemented measures seem to be ineffective because healthy food prices continue to increase.

Although, in the Kingdom of Saudi Arabia (KSA) there are limited studies compared to other countries, there are some studies which describe the change in food consumption along with the economic growth of the country. Currently, the Saudi market is majorly dependent *Corresponding Author: Dr. Despena Andrioti, Centre of Maritime Health and Society, Institute of Public Health, School of Health Sciences, University of Southern Denmark, Campusvej 55, 5230 Odense M, Denmark, Tel: +4565509391; E-mail: dandrioti@health.sdu.sk

Citation: Al-Aklabi N, Al-Dowsari W, Andrioti D (2016) Investigating the Correlation between Food Prices and University Students Awareness of the Effects of Fast Food Consumption on their Health. Int $\mathrm{J}$ Community Fam Med 1: 114. doi: https://doi.org/10.15344/2456-3498/2016/114

Copyright: () 2016 Al-Aklabi et al. This is an open-access article distributed under the terms of the Creative Commons Attribution License, which permits unrestricted use, distribution, and reproduction in any medium, provided the original author and source are credited. 
Citation: Al-Aklabi N, Al-Dowsari W, Andrioti D (2016) Investigating the Correlation between Food Prices and University Students Awareness of the Effects of Fast Food Consumption on their Health. Int J Community Fam Med 1: 114. doi: https://doi.org/10.15344/2456-3498/2016/114

Page 2 of 5

on imports to cover its domestic demand for nutritious products. The food consumption patterns of Saudi society have been influenced by changes over the last 30 years due to economic growth and the increase on oil revenues. Saudi consumers are vulnerable to the changes of global food prices. The Saudi low-income households are more at risk of high food prices, thus reducing equity and efficiency standards [15]. Furthermore Saudi females living in Riyadh are turning more and more to fast food and the reason of this transition according to the participants in the study is that the taste of fast food was excellent $(80.6 \%)$ and the price of fast food was acceptable (82.7\%) [6].

Sedentary lifestyles are becoming particularly prevalent among Saudi people, especially females, for most of them do not engage in physical activity [17]. However, female students reported a higher interest in their body image shown by a higher prevalence of dieting, greater positive attitudes toward healthy eating, and greater interest in their health and body weight, than their male counterparts. Moreover female students are more likely to be respondents for nutrition education programs $[16,17]$.

The University of Malaysia Pahang (UMP) published a study investigating fast food consumption among university students [18] The study of UMP sought to determine the level of awareness students had about fast food consumption and related health outcomes, which is also part of our objectives. With regards to the association between price and food quality there are no available studies in Princess Nora University (PNU) addressing the same subject.

This mixed methods study [19] addresses the link between food price and quality of food while also determining the level of awareness of PNU students about possible influences of fast food consumption on their health.

\section{Material and Methods}

\section{Study design}

An explanatory sequential mixed methods design was used, and it involved collecting quantitative data first and then complementing the results with qualitative data, which may provide a better understanding of the research objectives than either type alone [20] In the quantitative phase of the study a questionnaire was distributed to the students at PNU. The qualitative phase was conducted as a follow-up to complement the quantitative results.

\section{Setting}

The study was conducted in student affairs (A10) at PNU, where the university canteens are located. There are 10 canteens in total in this building.

\section{Duration of study}

The study was conducted over a period of two months (4th Oct 2015 - 6th Dec 2015).

\section{Sample size and sampling technique}

A sample size of 100 female students was selected randomly. During workdays, the researchers personally asked every other student, entering the building, if they were willing to participate in this research by answering the questionnaire. All participants were informed that the questionnaire would be anonymous. The working staff, including teachers, security personnel, cleaning staff, workers at the canteens and/or shops, were excluded from the study [21,22].

\section{Data collection}

The questionnaire was based on international bibliography and more specifically on the questionnaire published in the Sudanese Journal of Public Health, adapted to the Saudi Arabian environment [23]. Before distributing the questionnaire, a pilot test involving 10 students was conducted to ensure the questions were fully understandable. Responses to questions were in the form of agree/ neutral/disagree [22]. Further, data were gathered by observing the busy canteens and making a list of the products that had the most demand.

\section{Data analysis}

The data collected was analysed using Microsoft's Excel 2010 [24]. The chosen method for analysis was the numerical counts-frequencies (percentage).

\section{Ethical considerations}

The approval of the A10 Students Affairs administration as well as that of the college of Health and Rehabilitation Sciences was necessary to conduct the study. The participants answered the questionnaire voluntarily, were aware of the objectives and were asked to sign a paper confirming their agreement to participate (i.e. informed consent). The answers to the questionnaire were collected in a ballot box securing the anonymity and confidentiality of the participants.

\section{Results}

(a) Quantitative analysis :

\begin{tabular}{|c|c|c|}
\hline Characteristics & Frequency $(\mathrm{n}=100)$ & Percentage \\
\hline \multicolumn{3}{|l|}{ Year of birth } \\
\hline $1990-1992$ & 22 & $22 \%$ \\
\hline 1993-1995 & 58 & $58 \%$ \\
\hline 1996-1997 & 20 & $20 \%$ \\
\hline \multicolumn{3}{|l|}{ College } \\
\hline $\begin{array}{l}\text { Health science } \\
\text { colleges }\end{array}$ & 17 & $17 \%$ \\
\hline Humanity colleges & 13 & $13 \%$ \\
\hline Community colleges & 25 & $25 \%$ \\
\hline $\begin{array}{l}\text { Deanships and } \\
\text { Institutes }\end{array}$ & 1 & $1 \%$ \\
\hline Other & 44 & $44 \%$ \\
\hline \multicolumn{3}{|l|}{$\begin{array}{l}\text { Income per week } \\
\text { (Pocket Money } 100 \\
\text { SAR=24 EURO) }\end{array}$} \\
\hline $0-49$ & 33 & $33 \%$ \\
\hline 50-149 SAR & 49 & $49 \%$ \\
\hline 150-299 SAR & 15 & $15 \%$ \\
\hline$>300$ SAR & 3 & $3 \%$ \\
\hline Total & 100 & $100 \%$ \\
\hline
\end{tabular}

Int J Community Fam Med

ISSN: 2456-3498

IJCFM, an open access journal Volume 1. 2016. 114 
Citation: Al-Aklabi N, Al-Dowsari W, Andrioti D (2016) Investigating the Correlation between Food Prices and University Students Awareness of the Effects of Fast Food Consumption on their Health. Int J Community Fam Med 1: 114. doi: https://doi.org/10.15344/2456-3498/2016/114

Page 2 of 5

Table 1 shows that almost half of the students (58\%) who participated in the study were 20-22 years old. Moreover, almost half of them (44\%) come from various other colleges, whereas the remaining percentage was distributed between Health Science Colleges, Humanity Colleges and Community Colleges.

With regards to spare money per week half of the students (49\%) get 50-149 SAR per week while a third of the students (33\%) answered that they get 0-49 SAR per week.

\begin{tabular}{|l|l|l|}
\hline Variables & Frequency $(\mathrm{n}=100)$ & Percentage \\
\hline Strongly Agree & 36 & $36 \%$ \\
\hline Agree & 44 & $44 \%$ \\
\hline Neutral & 13 & $13 \%$ \\
\hline Disagree & 5 & $5 \%$ \\
\hline Strongly Disagree & 2 & $2 \%$ \\
\hline Total & 100 & $100 \%$ \\
\hline
\end{tabular}

Table 2: Do food prices influence your choice of food?

Table 2 shows how students responded as to whether food prices influence their choice of food. More specifically $80 \%$ (eight out ten) students pointed out that the prices affect their choices in relation to the food.

\section{Environment (restaurants)}

With regards to the cost of fast food, $88 \%$ of the respondents answered that food does cost a lot but nevertheless fast food costs less compared to healthy food. Above all, we found that the number of healthy food restaurants was considerably smaller than that of fast food restaurants and half of the respondents (50\%) "positively agree" to that. As to whether the existing restaurants serve more fast food that healthy food, the majority of students $(60 \%)$ responded that they "agree". Asking the responding students to evaluate the university canteens as either serving healthy food, fast food, or both, we found that $40 \%$ of them thought that the canteens were serving basically fast food, $32 \%$ of them considered the canteens served healthy food, and $28 \%$ of them would classify the canteens as serving both types.

\section{Knowledge (awareness)}

We asked the students if they were aware that consumption of fast food influences their health and what their beliefs were with regards to the association of nutritional value with food prices.

Figure 1 shows that the majority of the students (63\%) agreed and strongly agreed that the consumption of unhealthy food impacts their health

Furthermore, the students were well aware of the consequences of consuming fast food. Indeed, all respondents understood that consuming fast food frequently has implications for their health with obesity as most prevalent. When asked about the consequences that result from frequent consumption of fast food, $36 \%$ mentioned obesity and $21 \%$ mentioned heart disease, although they were less cognizant of other diseases.

Figure 2 illustrates that $63 \%$ of the respondents agreed and strongly agreed that there is a correlation between food quality and food price.

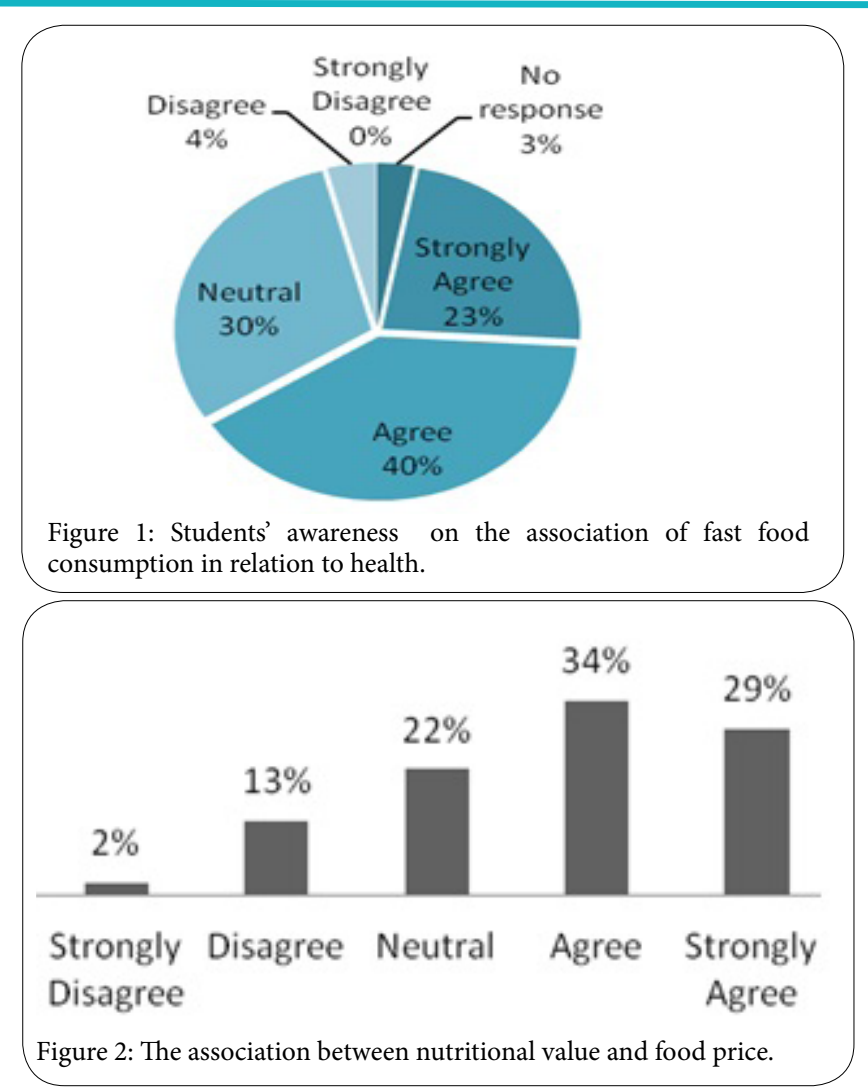

(b) Qualitative analysis

During the study we visited the restaurants/canteens of the University every day for a personal opinion on the students attitudes. These are located at the building A10 to serve the total population of the University. In this there are 10 restaurants/canteens which serve a variety of dishes traditional and/or ethnic. Based on our observation at the canteens of the University out of the ten canteens only three were serving healthy food. We looked at the prices in these canteens and we found them higher than those serving fast food. It was also observed that most of the girls bought food from the fast food canteens and as a result those were more crowded than the other canteens. Most of the crowded canteens have moderate prices. Notable is the fact that many fast food canteens provided at least some healthy options such as fresh orange juice, but at a price higher compared to that of soft drinks. Also, a few of the canteens served various kinds of salads such as green salads, mixed salads and fruit salads with a price between 12 to $16 \mathrm{SAR}$, which is considered a high price.

Upon closer inspection, the prices of healthy foods were found to be disproportionately higher than those of fast food. For example, with regards to prices of drinks, the price of a "cola type" soft drink was only 1.50-2 SAR versus fresh orange juice which cost over 10 SAR. With regards to food, a croissant cost 6 SAR versus a diet tuna sandwich at 15 SAR.

\section{Discussion}

The lifestyle of Saudi Arabian people has recently been influenced by globalization resulting in, broadly categorized, dietary and sedentary changes.6 Recent studies found that there exists an association between price and the quality of food which means nutritious food usually costs more [8]. 
Citation: Al-Aklabi N, Al-Dowsari W, Andrioti D (2016) Investigating the Correlation between Food Prices and University Students Awareness of the Effects of Fast Food Consumption on their Health. Int J Community Fam Med 1: 114. doi: https://doi.org/10.15344/2456-3498/2016/114

Page 2 of 5

This issue is as much economic as it is a health related one. One should keep in mind that food is a finite source and nutritious food even more so, and that students rarely make good judges of their own health. People would rather enjoy short-term delights (fast food) than consider possible health issues that may arise at a later age. In spite of this, the study highlighted the association between price and the quality of food selected and determined the PNU students' level of awareness of possible influences fast food consumption may have on their health. A combination of quantitative and qualitative methods was used for this study.

Socio-demographic factors such as age, education, food cost and income affect patterns of food consumption. More than $50 \%$ of the respondents were aged between 20 and 22 years old (Table 1), which is the average age of PNU students. More than $70 \%$ of the respondents were from multiple colleges showing a representative sample of the survey (Table 1), because all campus students gather under the same premises for lunch.

With regards to spare money per week, we found that half of the students (49\%) get 50-149 SAR meaning that half of the students come from a middle-income group, while $33 \%$ get $0-49$ SAR per week belonging to a low-income group (Table 1). Further the survey showed that pocket money is spent on soft drinks and fast food because the prices of said items are cheaper than healthier alternatives. We examined students' level of awareness with regards to the link between price and food quality as well as the prices of the products themselves through observation to confirm whether fast food was indeed the cheapest option in PNU canteens. As was also found by several other studies the low-income group appears to be the major consumer of fast food due to its price and the fact that they usually choose to ignore the consequences of this consumption [5,7].

Current data demonstrates that the vast majority $(80 \%)$ of respondents agree that fast food prices are affecting their food choice (Figure 1). Overall, fast food was cheaper than healthy food and this appears to be one reason behind the increase in its consumption. As the respondents pointed out they were aware of the association of fast food on their health but never the less they need something to eat taking into consideration their pocket money.

The participants either agreed or strongly agreed that fast food was cheaper than healthy food. A study conducted in Riyadh city about the effects of high food prices on consumption patterns found that the prices of essential food products increased in recent years and that naturally leads to providing alternative products with lower cost but with questionable quality [15].

Recently, another study in Riyadh on the trends of fast food consumption among young adult Saudi girls, found that over $60 \%$ of young female adults consumed fast food once per week, while more than $20 \%$ of them consumed fast food twice or more on a weekly basis [6].

With regards to students' beliefs about consuming unhealthy food, $63 \%$ of them were aware of the consequences that unhealthy food had on their health (Figure 3). These results are in accordance with a study in India which found that $30 \%$ of students were not aware of the harmful effects of fast food consumption and they pointed out the fact that they were too young to get any chronic diseases [22].
Another study in India showed that people are aware of the association between fast food consumption and obesity or heart disease. By comparing our results with other studies we see a similarity in findings, namely students having reasonable awareness about fast food [14]. Our findings show that even though students were aware of the influence of fast food on their health, price affects their choice.

Half of the students agreed that the price in the canteens affects their food choice. Student awareness was high and the majority of them were aware of the risk factors due to consumption of fast food. However, such student knowledge cannot prevent or reduce fast food consumption. Therefore, most of PNU students consumed fast food although they were aware of the consequences, for their weekly pocket money could not cover the cost of healthy foods.

\section{Conclusion}

This report aims to study the association between price and the quality of food selected (consuming unhealthy food), whilst also aiming to determine student awareness about the possible influences this consumption has on their health. We found that there was obvious association between price and quality of selected food and that refers to fast food prices being extremely cheap in contrast to healthy food. We found that the majority of students had decent knowledge regarding the consequences of fast food consumption. Identifying the factors that increase fast food consumption may improve dietary patterns, but a sustained public health effort is also required to promote more responsible choices. Changing individual behaviour is difficult without addressing the context in which people make decisions. Initial significant steps are needed to make healthful food choices available, identifiable, and affordable to people of all levels of income. Our ultimate goal should be to structure a university environment in which healthy behaviours are the optimal defaults.

\section{Policy Implications}

We recommend that PNU improves its regulations regarding canteens, aiming to promote healthier choices, in contrast to the current situation. An integrated food policy is also mandated to make nutritious food more affordable to encourage lower-income students to consider healthier choices, and to even out broader socio-economic inequalities. A tax policy against fast food has indeed already been considered.

\section{Competing Interests}

The authors declare that they have no competing interestes

\section{Author Contributions}

NAA and WAD were involved in acquisition of data, performed statistical analyses and drafted the manuscript.

DA contributed to the study's conception and design, interpretation of data, and critically revised the manuscript.

All authors read and approved the final manuscript.

\section{Acknowledgements}

We would like to thank our professors and teaching assistant for supporting us to conduct the study. We are also thankful to all students who participated. 
Citation: Al-Aklabi N, Al-Dowsari W, Andrioti D (2016) Investigating the Correlation between Food Prices and University Students Awareness of the Effects of Fast Food Consumption on their Health. Int J Community Fam Med 1: 114. doi: https://doi.org/10.15344/2456-3498/2016/114

\section{References}

1. Von Braun $J(2015)$ The world food situation new driving forces and required actions. Washington, D.C.: IFPRI; 2007 24: 990-998.

2. Guinness L, Wiseman $V(2011)$ Introduction to health economics. (2nd edition), Maidenhead: McGraw-Hill/Open University Press UK.

3. Fox-Rushby J, Cairns J (2005) Economic evaluation. Maidenhead: Open University Press.

4. Bowman SA, Linn M, Gerrior SA, Basiotis PP (1998) The healthy eating index 1994-96. Washington, DC: US Department of Agriculture CNPP-5 202: $720-2600$

5. Darmon N, Lacroix A, Muller L, Ruffieux B (2014) Food price policies improve diet quality while increasing socioeconomic inequalities in nutrition. Int J Behav Nutr Phys Act 11: 66.

6. ALFaris N, Al-Tamimi J, Al-Jobair M, Al-Shwaiyat N (2015) Trends of fast food consumption among adolescent and young adult Saudi girls living in Riyadh. Food Nutr Res 59: 26488

7. Darmon N, Drewnowski A (2015) Contribution of food prices and diet cost to socioeconomic disparities in diet quality and health. Nutr Rev 73: 643-660.

8. Rao M, Afshin A, Singh G, Mozaffarian D (2013) Do healthier foods and diet patterns cost more than less healthy options?. BMJ Open 3: e004277.

9. Drewnowski A, Darmon N, Briend A (2004) Replacing fats and sweets with vegetables and fruits--a question of cost. Am J Public Health 94: 15551559.

10. Lobstein T, Davies S (2009) Defining and labelling 'healthy' and 'unhealthy' food. Public Health Nutr 12: 331-340.

11. Duffey KJ, Gordon-Larsen P, Shikany JM, Guilkey D, Jacobs DR Jr, et al (2010) Food price and diet and health outcomes: 20 years of the CARDIA Study. Arch Intern Med 170: 420-426.

12. Stewart H, Kuchler F (2015) USDA ERS - Price Trends Are Similar for Fruits, Vegetables, and Snack Foods USDA 55: 29

13. Maillot M, Darmon N, Darmon M, Lafay L, Drewnowski A (2007) Nutrientdense food groups have high energy costs: an econometric approach to nutrient profiling. J Nutr 137: 1815-1820

14. Lakdawalla D, Philipson T (2009) The growth of obesity and technological change. Econ Hum Biol 7: 283-293.

15. Yousif E, Al-Kahtani S (2014) Effects of high food prices on consumption pattern of Saudi consumers: A case study of Al Riyadh city. J Saud Soc Agri Sci 13: 169-173.

16. Drewnowski A, Specter SE (2004) Poverty and obesity: the role of energy density and energy costs. Am J Clin Nutr 79: 6-16.

17. Al-Hazzaa HM (2004) Prevalence of physical inactivity in Saudi Arabia: a brief review. East Mediterr Health J 10: 663-670.

18. Milalove, wahyda, sayha (Sakura sahara group) Fast Food (2011) It Is Fast but is it Food? : Fast Food Consumption among UMP Students. Malaysia: students of Faculty Technology at UMP.

19. Creswell J (2014) Research design. Qualitative, Quantitative, and Mixed Method Approaches. Thousand Oaks, California: SAGE Publications, Inc

20. Creswell J (2008) Educational research: Planning, Conducting, and Evaluating Quantitative and Qualitative Research. 3rd Ed .Upper Saddle River, NJ: Pearson Education.

21. DeLecce $T$ (2015) Survey Study: Definition \& Design.

22. Kowalczyk D (2015) Correlational Research: Definition, Purpose \& Examples.

23. VinayGopal J, Sriram S, Kannabiran K, Seenivasan R (2012) Student's perspective on fast foods: Survey. Suda J PH 7:21-25.

24. Arsham H (2015) Excel for Business Statistics. 